\title{
L-Tryptophan Implicated in Human Eosinophilia-Myalgia Syndrome Causes Fasciitis and Perimyositis in the Lewis Rat
}

\author{
Leslie J. Crofford,“ Jeanne I. Rader," Marinos C. Dalakas, ${ }^{5}$ Robert H. Hill, Jr.,' Samuel W. Page," Larry L. Needham,' \\ Linda S. Brady, ${ }^{\ddagger}$ Melvyn P. Heyes, ${ }^{\ddagger}$ Ronald L. Wilder, ${ }^{*}$ Philip W. Gold, ${ }^{\ddagger}$ Isabel Illa, ${ }^{6}$ Craig Smith, ${ }^{\ddagger}$ \\ and Esther M. Sternberg** \\ ${ }^{*}$ National Institute of Arthritis and Musculoskeletal and Skin Diseases, ${ }^{\ddagger}$ National Institute of Mental Health, and ${ }^{\S}$ National Institute of \\ Neurological Disorders and Stroke, Bethesda, Maryland 20892; "Center for Food Safety and Applied Nutrition, Food and Drug \\ Administration, Washington, DC 20204; and 'Centers for Disease Control, Atlanta, Georgia 30333
}

\begin{abstract}
Tryptophan-associated eosinophilia-myalgia syndrome (LTRP-EMS) is a newly described syndrome which occurred in epidemic fashion in the United States in the summer and fall of 1989. Epidemiologic data has linked the syndrome to intake of L-tryptophan (L-TRP) from one specific manufacturer, but the precise etiologic compound(s) must be established by replication of the syndrome in an appropriate animal model.

In this study, implicated L-TRP, United States Pharmacopeia (USP) grade L-TRP, or vehicle was administered by gavage in a blinded fashion for $38 \mathrm{~d}$ to female Lewis rats at doses comparable with those ingested by patients who developed the eosinophilia-myalgia syndrome. Animals receiving implicated L-TRP, but not those receiving USP grade L-TRP or vehicle, developed histologic signs consistent with fasciitis and perimyositis, specific pathologic features of human L-TRP-EMS. Peripheral blood eosinophilia was not observed. Hypothalamic corticotropin releasing hormone mRNA levels were lower and plasma corticosterone levels tended to be lower in the animals that received implicated L-TRP. Plasma L-kynurenine was higher in both L-TRP-treated groups compared to the vehicletreated animals.

The female Lewis rat is known to be susceptible to a wide variety of inflammatory diseases. Identification of specific inflammatory changes in this rat following exposure to implicated L-TRP indicates that this animal model will be important in subsequent investigations into the etiology, pathogenesis, and treatment of human L-TRP-EMS. (J. Clin. Invest. 1990. 86:1757-1763.) Key words: inflammatory changes - muscle pathology • glucocorticoids • hypothalamic-pituitary-adrenal axis • serotonin
\end{abstract}

\section{Introduction}

We and others have recently described L-tryptophan-related eosinophilia myalgia syndrome (L-TRP-EMS) ${ }^{1}$ in patients

Address reprint requests to Dr. Sternberg at NIMH, Building 10 Room 3S231, 9000 Rockville Pike, Bethesda, MD 20892.

Received for publication 10 August 1990 and in revised form 4 September 1990.

1. Abbreviations used in this paper: LEW/N, Lewis rat; L-TRP, L-tryptophan; L-TRP-EMS, L-TRP-eosinophilia myalgia syndrome.

The Journal of Clinical Investigation, Inc.

Volume 86, November 1990, 1757-1763 taking the amino acid L-tryptophan (L-TRP) for insomnia, depression, and other disorders (1-4). L-TRP-EMS is characterized initially by eosinophilia, myalgias, and edema, and subsequently by myositis, fasciitis, skin sclerosis, and peripheral neuropathy $(2,4,5)$. Occurrence of this syndrome reached epidemic proportions in the United States in the summer and fall of 1989 and by June 1990, at least 1,500 cases including 26 deaths had been reported $(5,6)$.

The etiology and pathogenesis of the syndrome are not yet clear. However, several lines of evidence suggest that a contaminant(s) of L-TRP may trigger the syndrome. Epidemiologic studies have linked the development of L-TRP-EMS to ingestion of L-TRP from one manufacturer (7-9). Retail lots of L-TRP from the implicated manufacturer that were associated with cases of L-TRP-EMS (case-associated L-TRP) were significantly more likely to have been produced from January through June, 1989 than were other lots from this manufacturer that were taken by asymptomatic control subjects (7-9). It has been proposed that a contaminant(s) or a by-product of a specific manufacturing and/or purification process used by the implicated manufacturer is responsible for the epidemic occurrence of L-TRP-EMS (7-9). An animal model is important to identify a cause and effect relationship between contaminated L-TRP and the development of L-TRP-EMS and to define the pathogenesis of this complex syndrome.

In previous studies, we showed that female Lewis (LEW/N) rats are susceptible to many inflammatory diseases in response to a wide range of inflammatory stimuli (10-12). We suggested that the pattern of disease that $\mathrm{LEW} / \mathrm{N}$ rats develop is related to the specific inflammatory stimulus to which they are exposed, while their general increased susceptibility to inflammation is related to a defect in induction of the counter-regulatory corticosteroid response (10-12).

In this report, we show that LEW/N rats treated with implicated L-TRP but not with United States Pharmacopeia (USP) grade L-TRP or vehicle developed many of the specific features of L-TRP-EMS including perimyositis, fasciitis, and perivascular inflammation. Peripheral blood eosinophilia was not observed.

\section{Methods}

Animals. 36 6-wk-old female, virus antibody-free LEW/N rats weighing $\sim 100 \mathrm{~g}$ were obtained from Harlan-Sprague-Dawley (Indianapolis, IN). Rats were randomly divided into three groups of 12 animals, housed two per cage in microisolator cages in laminar flow units and were handled in laminar flow hoods only. The animal room was 
maintained at $18-26^{\circ} \mathrm{C}$ and $40-70 \%$ humidity with a 12 -h-on/12-h-off light cycle. Purified diet AIN-76A (13) containing 0.2\% L-TRP was prepared by Dyets, Inc. (Bethlehem, PA) and provided in ceramic food bowls equipped with stainless steel lids and food followers. The rats were allowed free access to diet and distilled water throughout the study. Food consumption was measured weekly. Blood for total white blood cell and eosinophil counts was obtained by tail bleed into heparinized microcapillary tubes on the first day of the study and at weekly intervals therafter.

L-Tryptophan samples. Two samples of L-TRP were used in this study. One sample, "implicated L-TRP", was produced by the implicated manufacturer (7-9) in July 1989. The HPLC profile of the implicated L-TRP (Fig. $1 A$ ) is similar to that of an L-TRP-EMS case-associated lot (Fig. $1 \mathrm{~B}$ ) formulated by the implicated manufacturer in June 1989. The second sample used in this study was USP grade L-TRP from a nonimplicated manufacturer (Fig. $1 C$ ). The two L-TRP samples were blind-coded by the Centers for Disease Control and provided to the Food and Drug Administration, the National Institute of Mental Health, and the National Institute of Arthritis and Musculoskeletal and Skin Disease for animal testing.
HPLC profiling. Methanol-water extracts were prepared and profiled by gradient elution from Partisil 5 ODS 3 columns (Whatman Inc., Clifton, NJ) using acetonitrile/water/trifluoroacetic acid (Fig. 1).

Treatments. Suspensions of L-tryptophans were prepared in aqueous $0.5 \%$ methylcellulose (MC) (M-0387, Sigma Chemical Co., St. Louis, MO) and administered to rats daily by gavage in volumes of $0.8-0.9 \%$ of body weight. The dosage of each L-TRP was $1,600 \mathrm{mg} / \mathrm{kg}$ per $d$ per rat and was equivalent to a human consumption of $\sim 5$ $\mathrm{g} / \mathrm{d}$. This dose is within the range of amounts of L-TRP consumed by persons who developed the L-TRP-EMS syndrome $(0.5-15 \mathrm{~g} / \mathrm{d})(2$, $5,7)$. The animal protocol was approved by the Animal Care and Use Committee of the National Institute of Mental Health.

Sample collection. The study was terminated after $38 \mathrm{~d}$. Animals were euthanized by decapitation $24 \mathrm{~h}$ after the final gavage. Blood was collected in sodium citrate for cell counts and differential. Additional blood was centrifuged at $4^{\circ} \mathrm{C}, 2,000 \mathrm{~g}$ and plasma samples were stored at $-70^{\circ} \mathrm{C}$. Brains were removed and frozen immediately in isopentane cooled to $-160^{\circ} \mathrm{C}$ then stored at $-80^{\circ} \mathrm{C}$.

Histopathology. A portion of the gastrocnemius muscle of one hind leg was removed and frozen in isopentane cooled to $-160^{\circ} \mathrm{C} .10-\mu \mathrm{m}-$

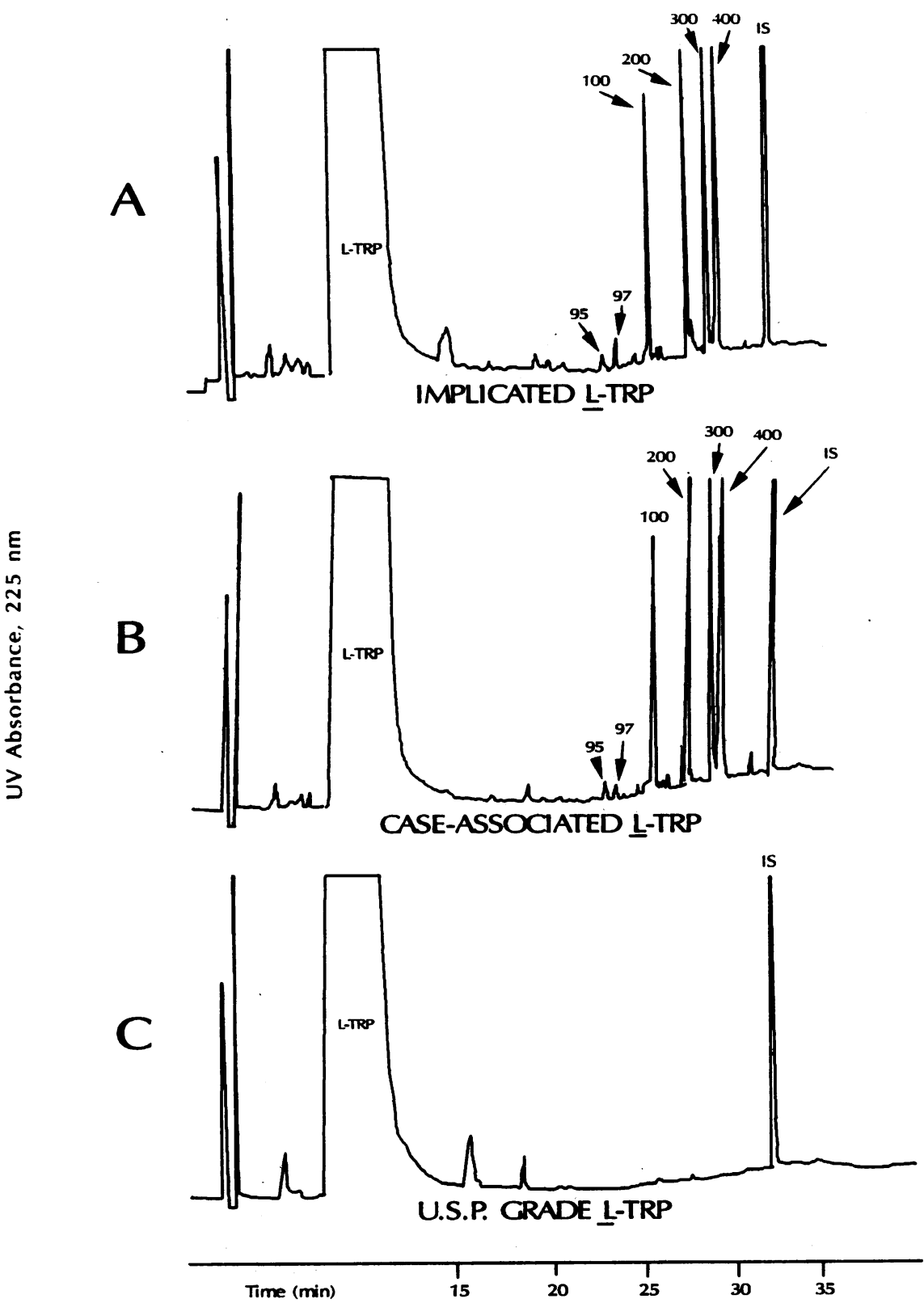

Figure 1. HPLC profiles of L-tryptophan. ( $A$ ) Implicated L-TRP. L-TRP manufactured in July 1989 by the same manufacturer as case-associated L-TRP. This product did not reach the market because of the 17 November 1989 Food and Drug Administration recall. (B) Case-associated L-TRP. Retail lot of L-TRP from the implicated manufacturer that was associated with development of cases of L-TRP-EMS. (C) USP grade L-TRP. $1 \mathrm{ml}$ of $50 \%$ methanol/water containing an internal standard (2,3-dichlorophenol) was added to a tube containing $10 \mathrm{mg}$ of L-TRP. Samples were vortexed and centrifuged, and $100 \mu \mathrm{l}$ of the supernatant were injected into a Waters Associates HPLC. The column used was a Partisil 5 ODS 3 (Whatman Inc.). A gradient program was used at $2 \mathrm{ml} / \mathrm{min}$ with mobile phase A (10\% acetonitrile and $0.1 \%$ trifluoroacetic acid in water) and mobile phase B $(50 \%$ acetonitrile and $0.1 \%$ trifluoroacetic acid in water). The linear gradient was as follows: initial, $100 \% \mathrm{~A}$; at $20 \mathrm{~min}$, $63 \% \mathrm{~A}$ and $37 \% \mathrm{~B}$; at $30 \mathrm{~min}, 100 \% \mathrm{~B}$; at $38 \mathrm{~min}, 100 \% \mathrm{~B}$; and at $38.1 \mathrm{~min}, 100 \% \mathrm{~A}$ (end of run). Eluted peaks were monitored at $225 \mathrm{~nm}$. 
thick sections of fresh-frozen muscle were processed for modified trichrome and muscle enzyme histochemistry as previously described (14). Two of us independently viewed the biopsies in a blinded fashion on coded slides and scored for degree of inflammation according to the number of counted inflammatory foci. The thickness of the fascia in the biopsies was measured directly from the slides, also in a blinded fashion, using a built-in micrometer.

Hind limbs for skin histology were removed and fixed in $10 \%$ neutral formalin. Lungs were inflated with $10 \%$ neutral formalin before fixation. The specimens were embedded in paraffin blocks, sectioned, and stained with hematoxylin and eosin by Metpath, Inc. (Rockville, MD).

Hematology. Total white blood cells were counted with a Coulter Counter. The values reported are the means of two determinations per sample. One observer, blinded to the identity of the groups, performed eosinophil counts as differentials of individual smears stained with Wright's stain. Lack of eosinophilia was corroborated by a second observer. Identification was based upon morphological and staining characteristics.

Biochemical assays. Plasma corticosterone levels were determined by radioimmunoassay (11). Plasma kynurenine was assayed as described previously (15).

In situ hybridization. A synthetic 48-base oligodeoxyribonucleotide probe for rat corticotropin-releasing hormone (16) was labeled at the $3^{\prime}$-end with $\left[\alpha^{-35}\right.$ S $]$ dATP (sp act $>1,000 \mathrm{Ci} / \mathrm{mmol}$, New England Nuclear, Boston, MA) using terminal deoxynucleotidyl transferase (25 $\mathrm{U} / \mu \mathrm{l}$, Boehringer-Mannheim Inc., Indianapolis, IN). Sense and antisense ribonucleotide probes for the glucocorticoid receptor (17) and mineralocorticoid receptor (18) were generated using the Riboprobe System (Promega Biotech, Madison, WI) in the presence of $\left[\alpha-{ }^{35}\right.$ S UTP (sp act $1,000-1,500 \mathrm{Ci} / \mathrm{mmol}$, New England Nuclear).

In situ hybridization histochemistry was performed on sections of frozen brain tissue and message was quantitated as previously described (19). Light transmittance for each probe was made on four consecutive sections per rat with the average used to calculate the group mean.

Statistical analyses. Statistical analyses included an analysis of variance (ANOVA) and separation of means by Duncan's multiple range tests (20). For in situ hybridization, significance between control and experimental groups was determined by one-way analysis of variance and the Sheffe F-test (21) utilizing commercially available software (StatView 2; Abacus Concepts, Inc., Berkeley, CA).

\section{Results}

\section{Animals}

By clinical observation, no consistent differences among groups were found during testing. No significant differences in weight gain (mean $\pm \mathrm{SD}$ ) occurred among groups of rats after $38 \mathrm{~d}$ of treatment (vehicle: $57 \pm 9$; USP grade L-TRP: $50 \pm 8$; and implicated L-TRP: $55 \pm 6$ ). Two of 12 rats in the USP grade and three of 12 rats in the implicated L-TRP-treated groups died as a result of gavage-related trauma (esophageal perforation). Autopsies confirmed the cause of death in each case. For all animals, viral titers to rat coronavirus and sialodacryoadenitis virus, performed by ELISA (Microbiological Associates, Inc., Rockville, MD) at study termination were negative.

\section{Pathology}

Muscle and fascia. Muscle biopsy specimens from rats that received implicated L-TRP showed changes similar to those seen in cases of human L-TRP-EMS $(2,4,22)$. The characteristic findings include inflammatory infiltrates in the fascia and perimysial spaces consisting of mononuclear cells forming "islands" around small perimysial blood vessels (Fig. 2, $a$ and $b$ and Table I). The lumen wall of some vessels was narrowed or obliterated by the infiltrating mononuclear cells (Fig. $2 c$ ). Eosinophils were not noted by light microscopy. In addition to these changes, in biopsies of rats treated with implicated L-TRP there was significant $(P<0.01)$ thickening of the fascia and the perimysial septae (Fig. $2, b$ and $d$, and Table I). We also observed mild to moderate proliferation of perimysial connective tissue (Fig. $2 d$ ) with fibroblastic proliferative changes on all biopsy specimens from the implicated L-TRP treatment group but only in three of 10 biopsies in each of the USP grade L-TRP and vehicle-treated groups. The number of counted fibroblastic cells in the perimysial tissue of the implicated L-TRP-treated group was not, however, significant compared to the other groups. A tendency for small fiber type grouping (up to 12 fibers) was also noted in the implicated L-TRP-treated animals as compared to some smaller size groupings (up to eight fibers) seen in other groups. This could be indicative of mild chronic denervation with reinnervation in the rats receiving implicated L-TRP. In these animals, mild inflammation was seen around occasional nerve trunks traveling along major interfascicular vessels. Rare sites of endomysial inflammation with phagocytosis of isolated muscle fibers especially in the periphery of the fascicles were also noted.

Lung/skin. In this study, lung histopathology showed no differences among the L-TRP-treated and vehicle-treated groups. Specifically, we found no evidence of perivascular infiltrates, vasculitis, or granulomatous changes. Sections of skin revealed no specific differences among groups.

\section{Hematology}

Total white blood cell counts and eosinophil counts were not significantly different among groups and did not change over the course of the study. Total white blood cell counts at day 0 and day 38 (mean $\times 10^{3} / \mathrm{mm}^{3} \pm \mathrm{SD}$ ) for the vehicle, USP grade L-TRP, and implicated L-TRP-treated groups, respectively, were $8.5 \pm 1.9$ and $8.5 \pm 1.7 ; 7.8 \pm 1.2$ and $8.2 \pm 1.2$; and $6.7 \pm 1.2$ and 7.8 \pm 1.5 . The mean eosinophil count remained $\leq 1 \%$ of 100 cells counted by manual differential for all groups at all weekly intervals and at study termination. The eosinophil counts for all animals was within the normal range $(0-5 \%)$ throughout the study.

Table I. Histopathology of Muscle and Fascia

\begin{tabular}{lccc}
\multicolumn{1}{c}{ Muscle/fascia biopsy } & $\begin{array}{c}\text { Group 1 } \\
n=10\end{array}$ & $\begin{array}{c}\text { Group 2 } \\
n=10\end{array}$ & $\begin{array}{c}\text { Group 3 } \\
n=9\end{array}$ \\
\hline $\begin{array}{l}\text { Islands of perimysial } \\
\quad \text { inflammatory cells }\end{array}$ & & & \\
$\begin{array}{l}\text { No. of animals affected } \\
\text { No. of "islands" per biopsy } \\
\quad \text { Mean } \pm \text { SD }\end{array}$ & 1 of 10 & 0 of 10 & 7 of 9 \\
$\quad$ Range & $0.4 \pm 1.8$ & 0 & $4.6 \pm 5.0^{*}$ \\
$\begin{array}{l}\text { Thickness of fascia } \\
\text { Mean } \pm \text { SD ( } \mu \mathrm{m})\end{array}$ & $0-6$ & 0 & $3-18$ \\
Range & $63 \pm 29$ & $71 \pm 15$ & $131 \pm 99^{\ddagger}$ \\
& $25-130$ & $40-100$ & $30-450$
\end{tabular}

Group 1, vehicle; group 2, USP grade L-TRP; group 3, implicated L-TRP. "Islands" of inflammation were counted on coded slides by two independent observers. Thickness of fascia was determined with built-in micrometer by two observers blinded to the identity of the groups. ${ }^{*} P<0.05$ from groups 1 and $2{ }^{\ddagger} P<0.01$ from groups 1 and 2. 

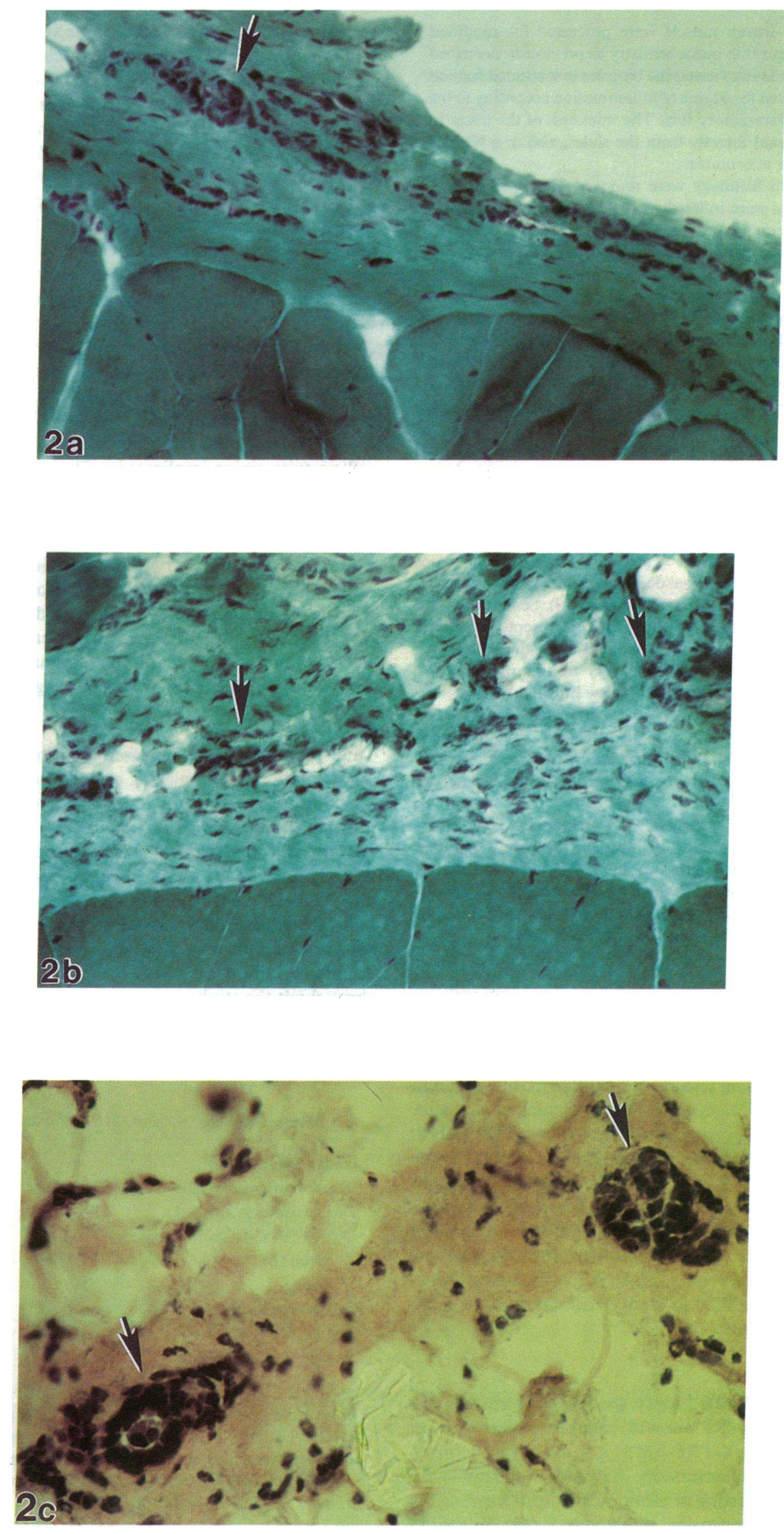

1760 Crofford et al. 


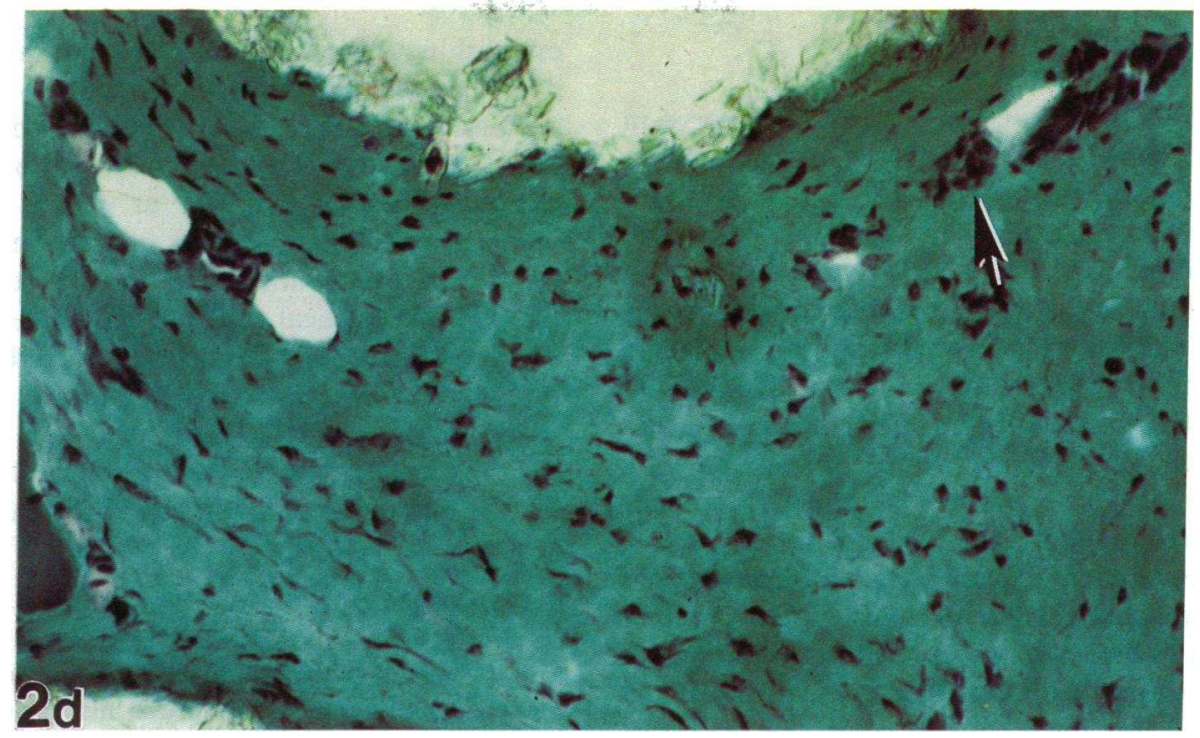

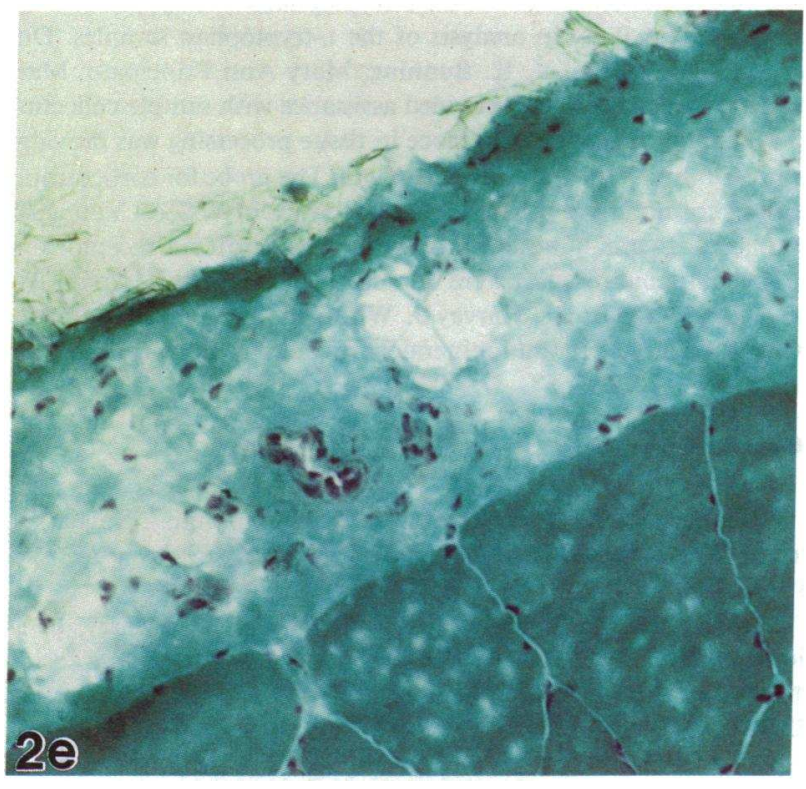

\section{Plasma corticosterone}

Serum corticosterone levels (nanograms per milliliter, mean \pm SEM) for the vehicle group $(173 \pm 41, n=10)$ and USP grade L-TRP $(157 \pm 38, n=10)$ group were similar to those we have reported for LEW/N rats $(11,12)$. The mean plasma corticosterone in the implicated L-TRP-treated group was lower than that of the other groups $(91 \pm 36, n=9)$, although this difference did not reach statistical significance $(P<0.21)$ by ANOVA.

In situ hybridization of brain section

Corticotropin releasing hormone mRNA levels (mean \pm SD expressed as a percentage of the vehicle-treated group) were significantly $(P<0.05)$ decreased in the hypothalamic paraventricular nucleus in the implicated L-TRP-treated group $(88 \pm 8 \%)$ compared to the USP grade L-TRP-treated $(101 \pm 11 \%)$ and vehicle-treated groups $(100 \pm 8 \%)$. In the hip-
Figure 2. Histopathology of muscle and fascia. Transverse frozen sections of biopsies stained with modified Gomori trichrome $(a, b, d$ $e)$ and $\mathrm{H} \& \mathrm{E}(c)$. Inflammatory infiltrates surrounding small vessels forming "islands" are noted in the fascia and perimysium $(a, b)$ $(375 \times)$. Higher magnification of two endofascial vessels show perivascular inflammation, endothelial proliferation, and infiltration of the lumen wall by mononuclear cells $(c)(520 \times)$. The fascia in the implicated L-tryptophan-treated animals is thickened with scattered endofascial infiltrates $(d)(375 \times)$. Fascia from a vehicle-treated animal $(e)(375 \times)$ shows absence of inflammation and normal thickness of the fascia as compared to the same magnification of the affected animals $(b, d)$. There are also no perivascular infiltrates in the vehicle-treated animal $(e)$.

pocampus, mineralocorticoid receptor mRNA levels were also reduced $(P<0.05)$ in the implicated L-TRP-treated group $(82 \pm 11 \%)$ compared to the USP grade L-TRP $(94 \pm 9 \%)$ and vehicle-treated $(100 \pm 9 \%)$ groups. Glucocorticoid receptor mRNA levels were increased in both L-TRP-treated groups $(128 \pm 11 \%$ and $110 \pm 11 \%$ for USP grade and implicated, respectively) as compared to control $(100 \pm 13 \%)$, but the increase reached significance $(P<0.01)$ only in the USP grade L-TRP-treated group.

\section{Plasma-L-kynurenine}

Plasma L-kynurenine (L-KYN) levels in L-TRP-treated rats (micrometers, mean \pm SEM) were $5.86 \pm 0.91$ in the implicated group and $5.62 \pm 0.70$ in the USP group. They were signifcantly $(P<0.05)$ higher than the levels of vehicle-treated rats (3.26 \pm 0.36$)$. 


\section{Discussion}

The histologic changes in skin, fascia, muscle, and nerve in human L-TRP-EMS show a characteristic distribution of inflammatory cell infiltrates and fibrosis $(2,4,22)$. We have shown that specific and quantitatively significant perimysial and fascial changes develop in female LEW/N rats treated with implicated L-TRP but not in those treated with USP grade L-TRP or vehicle. There were no specific histologic changes and no differences between groups in the lung or skin. Peripheral blood eosinophilia was not seen, nor were eosinophils observed by light microscopy in the affected tissues. The lack of eosinophilia may relate to experimental design or a species difference, although eosinophilia does develop in rats used in experimental studies of allergic, parasitic, and nutritional diseases (23-26). The moderate degree of inflammation could be due to the duration of the study, species related differences in inflammatory responses, a dose-response effect dependent upon the amount of unknown contaminant(s) in the implicated L-TRP used, or the lack of peripheral eosinophilia, if eosinophil degranulation products play a role in amplifying the inflammatory and/or fibrotic response $(3,4)$.

Implicated L-TRP-treated rats showed significantly lower hypothalamic corticotropin releasing hormone mRNA and hippocampal mineralocorticoid receptor mRNA levels, as well as a trend to lower plasma corticosterone levels, compared to the other groups of rats. A contaminant(s) structurally related to L-TRP with serotonin antagonist or benzodiazepine agonist activity could theoretically suppress the HPA axis (27-30). In light of our previously proposed hypothesis that enhanced susceptibility to inflammatory disease in the LEW/N rat is related to their deficient HPA axis-related counter-regulation of the inflammatory response $(2,10-12)$, a contaminant(s), with suppressive effects on the HPA axis, could amplify its own or other contaminant(s)' proinflammatory effects. In this regard the implicated peak 97 (Fig. 1) $(8,9)$ has been tentatively identified as di-L-tryptophan aminal of acetaldehyde (8) which could decompose to 1-methyl-1,2,3,4-tetrahydro- $\beta$-carboline3-carboxylic acid (8) a compound which could potentially have benzodiazepinelike activity (31).

In the present study, the increases in plasma L-KYN concentrations in the rats $24 \mathrm{~h}$ after the last L-TRP dose are consistent with the established effects of chronic loads of L-TRP on the kynurenine pathway (32). Further studies are required to define the role of these metabolites in the disease process in light of evidence that elevation of L-TRP metabolites can promote fibroblast proliferation $(33,34)$.

The clinical and histologic characteristics of L-TRP-EMS in humans are similar to a syndrome following administration of L-5-hydroxytryptophan and carbidopa (34), to other idiopathic inflammatory diseases of fibrous connective tissue, particularly eosinophilic fasciitis $(35,36)$, and to those observed in the toxic oil syndrome (TOS) that occurred in epidemic form in Spain in the spring of $1981(37,38)$. Epidemiologic studies of TOS linked the syndrome to adulterated rapeseed oil which was used as a cooking oil. Although the development of the syndrome was epidemiologically associated with certain impurities in the oil (e.g., oleyl anilide) (39), the etiology of TOS remains uncertain because an animal model reproducing the syndrome was never identified.

Animal models of human diseases allow the analysis of underlying etiologic and pathogenic events and are critical in establishing a cause-and-effect relationship between a putative etiologic agent and the development of a set of specific clinical symptoms and signs. Our study provides evidence that the female Lewis rat is a suitable animal in which to study the effects of implicated L-TRP as well as the complex factors involved in the pathogenesis of inflammatory, fibrosing syndromes of muscle and fascia. Further studies are required to identify the chemical structure of the contaminant(s) responsible for initiation of inflammation in L-TRP-EMS, as well as to determine whether such compounds can induce the syndrome in the absence of large doses of L-TRP. Finally, this animal model may be useful for testing potential treatment modalities for the human eosinophilia-myalgia syndrome.

\section{Acknowledgments}

The authors would like to thank Dr. Sheldon Cohen and Dr. Maria Turner for invaluable assistance in histologic examination of specimens. Dr. Steve Brandt is greatly appreciated for providing assistance with the Coulter Counter. We would like to thank Dr. Aldo Calogero for advice and critical review of the manuscript. Dr. Pat Mueller was responsible for procurement of the L-tryptophans. We appreciated the work of Sandra Baily in analysis of the L-tryptophan samples. Drs. Richard B. Rayburne, V. K. Bunning, Mary Ann Principato, Mary Truckess, and Joseph Betz provided assistance with sample collection and evaluation. Excellent assistance in tissue processing was provided by Guy Cunningham and Allison B. Lynn. The probe for corticotropin releasing hormone was generously donated by Dr. W. Scott Young III. The plasmids containing the probes for glucocorticoid receptor and mineralocorticoid receptor were donated by Dr. Jeffrey L. Arriza. We would like to thank Dr. Harvey J. Whitfield, Jr. for labeling of the glucocorticoid receptor and mineralocorticoid receptor probes.

\section{References}

1. Centers for Disease Control. 1989. Eosinophilia-myalgia syndrome: New Mexico. Morbidity and Mortality Weekly Reports. 38:765-767.

2. Silver, R. M., M. P. Heyes, J. C. Maize, B. Quearry, F. M Vionnet, and E. M. Sternberg. 1990. Scleroderma, fasciitis, and eosinophilia associated with the ingestion of tryptophan. N. Engl. J. Med. 322:874-881.

3. Hertzman, P. A., W. L. Blevins, J. Mayer, B. Greenfield, M. Ting, and G. J. Gleich. 1990. Association of the eosinophila-myalgia syndrome with the ingestion of tryptophan. N. Engl. J. Med. 322:869873.

4. Martin, R. W., J. Duffy, A. G. Engel, J. T. Lie, C. A. Bowles, T. P. Moyer, and G. J. Gleich. 1990. The clinical spectrum of the eosinophilia-myalgia syndrome associated with L-tryptophan ingestion. Ann. Intern. Med. 113:124-134.

5. Swygert, L. A., E. F. Maes, L. S. Daniel, L. Miller, H. Falk, and E. M. Kilbourne. 1990. Eosinophilia-myalgia syndrome: results of national surveillance. JAMA (J. Am. Med. Assoc.) In press.

6. Klontz, K. C., J. F. Cawley, D. L. Archer, and G. L. White. 1990. L-Tryptophan and the eosinophilia-myalgia syndrome: a new clinical entity. Physician Assistant. July:31-38.

7. Slutzger, L., F. C. Hoesly, L. Miller, L. P. Williams, J. C. Watson, and D. W. Fleming. 1990. Eosinophilia-myalgia syndrome associated with exposure to tryptophan from a single manufacturer. JAMA (J. Am. Med. Assoc.) 264:213-217.

8. Centers for Disease Control. 1990. Analysis of $L$-tryptophan for the etiology of eosinophilia-myalgia syndrome. Morbidity and Mortality Weekly Reports. 39:589-591.

9. Belongia, E. A., C. W. Hedberg, G. J. Gleich, K. E. White, A. N. Mayeno, D. A. Loegering, S. L. Dunnette, P. L. Pirie, K. L. MacDon- 
ald, and M. T. Osterholm. 1990. An investigation of the cause of the eosinophilia-myalgia syndrome associated with tryptophan use. $N$. Engl. J. Med. 323:357-365.

10. Sternberg, E. M., and R. L. Wilder. 1989. The role of the hypothalamic-pituitary-adrenal axis in an experimental model of arthritis. Prog. Neuro-Endocrine-Immunol. 2:102-108.

11. Sternberg, E. M., J. M. Hill, G. P. Chrousos, T. Kamilaris, S. J. Listwak, P. W. Gold, and R. L. Wilder. 1989. Inflammatory mediator-induced hypothalamic-pituitary-adrenal axis activation is defective in streptococcal cell wall arthritis-susceptible Lewis rats. Proc. Natl. Acad. Sci. USA. 86:2374-2378.

12. Sternberg, E. M., W. S. Young, R. Bernardini, A. E. Calogero, G. P. Chrousos, P. W. Gold, and R. L. Wilder. 1989. A central nervous system defect in biosynthesis of corticotropin-releasing hormone is associated with susceptibility to streptococcal cell wall-induced arthritis in Lewis rats. Proc. Natl. Acad. Sci. USA. 86:4771-4775.

13. American Institute of Nutrition. 1980. Second report of the American Institute of Nutrition Ad Hoc Committee on Standards for Nutritional Studies. J. Nutr. 110:1726.

14. Dalakas, M. C. 1987. Polymyositis and Dermatomyositis. Butterworth Publishers, Stoneham, MA. 347 pp.

15. Heyes, M. P., B. J. Quearry, and S. P. Markey. 1989. Systemic endotoxin increases L-tryptophan, 5-hydroxyindoleacetic acid, 3-hydroxykynurenine and quinolinic acid content of mouse cerebral cortex. Brain Res. 491:173-179.

16. Jingami, H., N. Mizuno, H. Takahashi, S. Shibahara, Y. Furutani, H. Imura, and S. Numa. 1985. Cloning and sequence analysis of cDNA for rat corticotropin-releasing factor precursor. Fed. Eur. Biochem. Soc. Lett. 191:63-66.

17. Miesfeld, R., S. Rusconi, P. J. Godowski, B. A. Maler, S. Okret, A. C. Wikstrom, J.-A. Gustafsson, and K. R. Yamamoto. 1986. Genetic complementation of a glucocorticoid receptor deficiency by expression of cloned receptor cDNA. Cell. 46:389-399.

18. Arizza, J. L., R. B. Simerly, L. W. Swanson, and R. M. Evans. 1988. The neuronal mineralocorticoid receptor as a mediator of glucocorticoid response. Neuron. 1:887-900.

19. Whitfield, H. J., Jr., L. S. Brady, M. A. Smith, E. Mamalaki, R. J. Fox, and M. Herkenham. 1990. Optimization of cRNA probe in situ hybridization methodology for localization of glucocorticoid receptor mRNA in rat brain: a detailed protocol. Cell. Mol. Neurobiol. 10:145-157.

20. Duncan, D. B. 1955. Multiple-range and multiple F tests. Biometrics. 11:1-42.

21. Winer, B. J. 1971. Statistical Principle in Experimental Design. McGraw-Hill Book Co., New York.

22. Clauw, D. J., D. J. Nashel, and P. Katz. 1990. Tryptophan-associated eosinophilic connective-tissue disease. A new clinical entity? JAMA (J. Am. Med. Assoc.). 263:1502-1506.

23. Capron, M., H. Bazin, M. Joseph, and A. Capron. 1981. Evidence for IgE-dependent cytotoxicity by rat eosinophils. J. Immunol. 126:1764-1768.

24. Capron, M., A. Capron, J.-P. Dessaint, G. Torpier, S. Gunnar,
O. Johansson, and L. Prin. 1981. Fc receptors for IgE on human and rat eosinophils. J. Immunol. 126:2087-2092.

25. Laylock, S. M., H. Smith, and B. A. Spicer. 1986. Airway hyper-reactivity and blood, lung, and airway eosinophilia in rats treated with Sephadex particles. Int. Arch. Allergy Appl. Immunol. 81:363-367.

26. Hong, C. B., and C. K. Chow. 1988. Induction of eosinophilic enteritis and eosinophilia in rats by vitamin $E$ and selenium deficiency. Exp. Mol. Pathol. 48:182-192.

27. Murphy, D. L., J. Zohar, B. A. Lawlor, T. Sunderland, T. A. Pigott, C. S. Aulakh, G. Bagdy, and N. A. Garrick. 1990. Hormonal responses to serotonergic drugs as a means to evaluate brain serotonergic function. In Serotonin: From Cell Biology to Pharmacology and Therapeutics. P. Paoletti, M. Vanhoutte, N. Brunello, and F. M. Maggi, editors. Kluwer Academic Publishers, Boston. 565-580.

28. Fernstrom, J. D., and R. J. Wurtman. 1971. Brain serotonin content: physiological dependence on plasma tryptophan levels. Science (Wash. DC). 173:149-153.

29. Calogero, A. E., G. Bagdy, K. Szemeredi, M. E. Tartaglia, P. W. Gold, and G. P. Chrousos. 1990. Mechanisms of serotonin receptor agonist-induced activation of the hypothalamic-pituitary-adrenal axis in the rat. Endocrinology. 47:303-308.

30. Kalogeras, J. T., A. E. Calogero, T. Kuribayiashi, I. Khan, W. T. Gallucci, M. A. Kling, G. P. Chrousos, and P. W. Gold. 1990. In vitro and in vivo effects of the triazolobenzodiazepine alprazolam on hypothalamic-pituitary-adrenal function: pharmacologic and clinical implications. J. Clin. Endocrinol. Metab. 70:1462-1471.

31. Buckholtz, N. S. 1980. Neurobiology of tetrahydro-beta-carbolines. Life Sci. 27:893-903.

32. Bender, D. A. 1982. Biochemistry of tryptophan in health and disease. Mol. Aspects Med. 6:101-197.

33. Seuwen, K., I. Magnaldo, and J. Pouyssegur. 1988. Serotonin stimulates DNA synthesis in fibroblasts acting through 5-HT1B receptors coupled to a Gi-protein. Nature (Lond.). 335:254-256.

34. Sternberg, E. M., M. H. Van Woert, S. N. Young, I. Magnussen, H. Baker, S. Guather, and O. C. Kirk. 1980. Development of a scleroderma-like illness during therapy with L-5-hydroxytryptophan and carbidopa. N. Engl. J. Med. 303:782-787.

35. Moutsopoulos, H. M., B. L. Webber, N. A. Pavlidis, G. Fostiropoulos, D. Goules, and L. E. Shulman. 1980. Diffuse fasciitis with eosinophilia: a clinicopathologic study. Am. J. Med. 68:701-709.

36. Lakhanpal, S., J. Duffy, and A. Engel. 1988. Eosinophilia associated with perimyositis and pneumonitis. Mayo Clin. Proc. 63:37-41.

37. Toxic Epidemic Study Group. 1981. Toxic epidemic syndrome, Spain. Lancet. ii:697-702.

38. Kilbourne, E. M., J. G. Rigau-Perez, C. W. Heath, M. M. Zack, H. Falk, M. Martin-Marcos, and A. DeCarlos. 1983. Clinical epidemiology of toxic oil syndrome. N. Engl. J. Med. 309:1408-1414.

39. Kilbourne, E. M., J. T. Bernert, Jr., M. Posada de la Paz, R. H. Hill, Jr., I. Abaitua Borda, B. W. Kilbourne, and M. M. Zack. 1988. Chemical correlates of pathogenicity of oils related to the toxic oil syndrome epidemic in Spain. Am. J. Epidemiol. 127:1210-1227. 